\begin{tabular}{|c|c|c|}
\hline $\begin{array}{l}\text { PKS } \\
\text { PUBLIC } \\
\text { KNOWLDGE } \\
\text { PROIJECT }\end{array}$ & $\begin{array}{c}\text { REVISTA DE GEOGRAFIA } \\
\text { (RECIFE) } \\
\text { http://www.revista.ufpe.br/revistageografia }\end{array}$ & 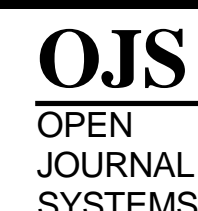 \\
\hline
\end{tabular}

\title{
GEOPROCESSAMENTO APLICADO AS \\ CARACTERÍSTICAS FÍSICAS E BIOFÍSICAS DA BACIA HIDROGRÁFICA DO RIO PARNAÍBA
}

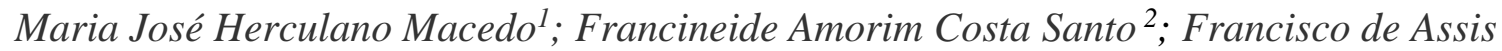 Salviano de Sousa ${ }^{3}$}

${ }^{1}$ Docente da Universidade Federal do Maranhão.Email: mariejhm@hotmail.com

${ }^{2}$ Docente da Universidade Federal do Cariri.Email:francyacs@hotmail.com

${ }^{3}$ Professor Titular da Universidade Federal de Campina Grande. Email: fsouza2011@ gmail.com

Artigo recebido em 20/06/2016 e aceito em 15/08/2017

\begin{abstract}
RESUMO
A presente pesquisa teve como objetivo realizar a analise das características físicas, biofísicas e o albedo, segundo as metodologias de Liang e Tasumi; o NDVI, Temperatura da superfície do solo e saldo de radiação segundo as metodologias SEBAL e METRIC na bacia hidrográfica do rio Parnaíba (BHRP). Para obtenção das informações biofísicas e saldo de radiação foram utilizadas imagens MODIS associadas aos Sistemas de Informações Geográficas para os anos 2005 e 2015. Os resultados obtidos revelaram que a BHRP apresenta forma alongada, não sendo, portanto suscetível a enchentes em situações normais de precipitação, apresenta baixa densidade de drenagem com predominância de declividade do tipo plana. As variáveis biofísicas e o saldo de radiação foram consistentes com os dados da literatura para diferentes coberturas do solo. As estimativas do albedo Liang e Tasumi revelaram padrões quando comparadas, e valores médios próximos. O saldo SEBAL apresentou melhor representação da BHRP em relação ao METRIC.
\end{abstract}

Palavras-chave: Morfometria; rede de drenagem; NDVI; saldo de radiação.

\section{APPLIED GEOPROCESSING AT PHYSICAL AND BIOPHYSICAL CARACTERISTS OF THE PARNAÍBA RIVER BASIN}

\begin{abstract}
This study aimed to carry out the analysis of the physical and biophysical caracteristics and of the albedo, according to the methodologies of Liang and Tasumi; NDVI, soil surface temperature and net radiation according to methodologies of the "SEBAL" and of the "METRIC" in the Parnaiba river basin (PRB). To obtain biophysical information and net radiation were used MODIS images associated with the Geographic Information System for the years 2005 and 2015. The results showed that the BHRP has elongated shape, and therefore not susceptible to flooding under normal rainfall conditions, It has low drainage density with predominant slope of flat type. The biophysical variables and the radiation balance were consistent with the literature for different ground covers. Estimates of albedo Liang and Tatsumi revealed patterns compared, and near average values. Estimates of albedo Liang and Tatsumi, revealed patterns when compared, and mean values close. The balance SEBAL showed better representation of the river basin in relation to "METRIC".

Keywords: Morphometry; drainage network; NDVI; radiation balance.
\end{abstract}




\section{INTRODUÇÃO}

Os dados de sensoriamento remoto aliado às técnicas de geoprocessamento constituem importante recurso para o monitoramento e gestão dos recursos naturais em nível de bacias hidrográficas. A aplicação de novas técnicas tais como Sistemas de Informação Geográfica (SIG) permitem analisar os aspectos técnicos, econômicos, sociais e ambientais do manejo de recursos hídricos e de prever os efeitos em termos do impacto antrópico.

As características físicas de uma bacia constituem elementos de grande importância para avaliação de seu comportamento hidrológico, pois, ao se estabelecerem relações e comparações entre elas e os dados hidrológicos conhecidos, pode-se determinar indiretamente os valores de variáveis hidrológicas em locais em que esses dados são desconhecidos (VILLELA; MATTOS, 1975).Diversos autores avaliam os processos quantitativos debacias hidrográficas através da analise de diversos parâmetros, tais como: densidade de drenagem, coeficiente de compacidade, índice de circularidade e forma da bacia, dentre outros (MILANI; CANALI, 2000; OLIVEIRA; BORSATO, 2011; WITHANAGE et al., 2014).

A orografia de uma região está diretamente associada à quantidade de radiação solar que a mesma recebe sobre sua superfície, dessa forma se torna interessante investigar as componentes do saldo de radiação ( $\mathrm{Rn})$ e a influência dessas sobre as mudanças no uso do solo em escalas de bacias hidrográficas.Essas componentes permitem a realização da analise dos processos biofísicos e possibilitam detectar e entender as modificações nas feições da superfície terrestre bem como as alterações climáticas ao longo do tempo (OLIVEIRA, 2012). Além disso, o estudo do saldo de radiação permite analisar os processos de evaporação, fotossíntese e aquecimentos do solo e do ar, e pode ser quantificado mediante a contabilidade entre os fluxos radiativos ascendentes e descendentes, incluindo ondas longas e curtas. A sua quantificação é fundamental para estudar as interações terra-atmosfera (BISHT; BRAS, 2010).

Alguns algoritmos são bastante utilizados para obtenção do saldo de radiação. O algoritmo SEBAL foi desenvolvido por Bastiaanssen (1995) e já foi validado em diversas campanhas experimentais por todo o mundo (BASTIAANSSEN et al., 1998; BASTIAANSSEN, 2000; TASUMI et al., 2005;SILVA et al., 2005; ANDRADE, 2008). Segundo Bastiaanssen et al. (1998) a vantagem do SEBAL em relação a outros algoritmos é a sua aplicabilidade em regiões heterogêneas e bacias hidrográficas para inferir o balanço de energia à superfície, que é também o grande objeto de aplicação do METRIC, que tem por 
base os princípios e técnicas utilizados pelo SEBAL, mas com uma inovação: uma auto calibração que elimina a necessidade de correção da temperatura da superfície e do albedo, medidos usando modelo de transferência radiativa (ALLEN et al., 2007).

A área de estudo do presente trabalho é a bacia hidrográfica do rio Parnaíba (BHRP). Essa bacia é uma das mais importantes regiões hidrográficas do Nordeste brasileiro, sendo ocupada pelos estados do Ceará, Piauí e Maranhão. Desta forma, o objetivo desse artigo consiste em analisar as características físicas e os componentes do saldo de radiação da BHRP através da utilização de imagens de satélites e de Sistemas de Informações Geográficas.

\section{MATERIAL E MÉTODOS}

\section{Descrição da Área de Estudo}

A região hidrográfica do rio Parnaíba situa-se entre as coordenadas $2^{\circ} 21^{\prime} \mathrm{S}$ e $11^{\circ} 06^{\prime} \mathrm{S}$ de latitude e $47^{\circ} 21^{\circ} \mathrm{W}$ e $39^{\circ} 44^{\prime} \mathrm{W}$ de longitude, ocupando uma área de $331441 \mathrm{~km}^{2}$, sendo 249497 km² no Piauí, 65492 km² no Maranhão, 13690 km² no Ceará e 2762 km² de área em litígio entre Piauí e Ceará. Essa região possui características climáticas peculiares, apresentando clima semiárido em sua porção oriental, sub-úmido em sua porção ocidental e úmido em sua porção sudoeste. Essa bacia apresenta uma heterogeneidade natural em função dos biomas existentes, com áreas de cerrado, caatinga, costeiro e transição entre CaatingaCerrado e Caatinga-Amazônia. Os solos na região são os latossolos, que apresentam boa fertilidade e são propícios para a agricultura. Os principais usos são para a pecuária, agricultura e urbanização, (BRASIL, 2006). A localização geográfica da região da bacia hidrográfica do rio Parnaíba pode ser observada na Figura 1. 
Figura 1 - Localização Geográfica da BHRP

REGIÃO HIDROGRÁFICA DO PARNAÍBA
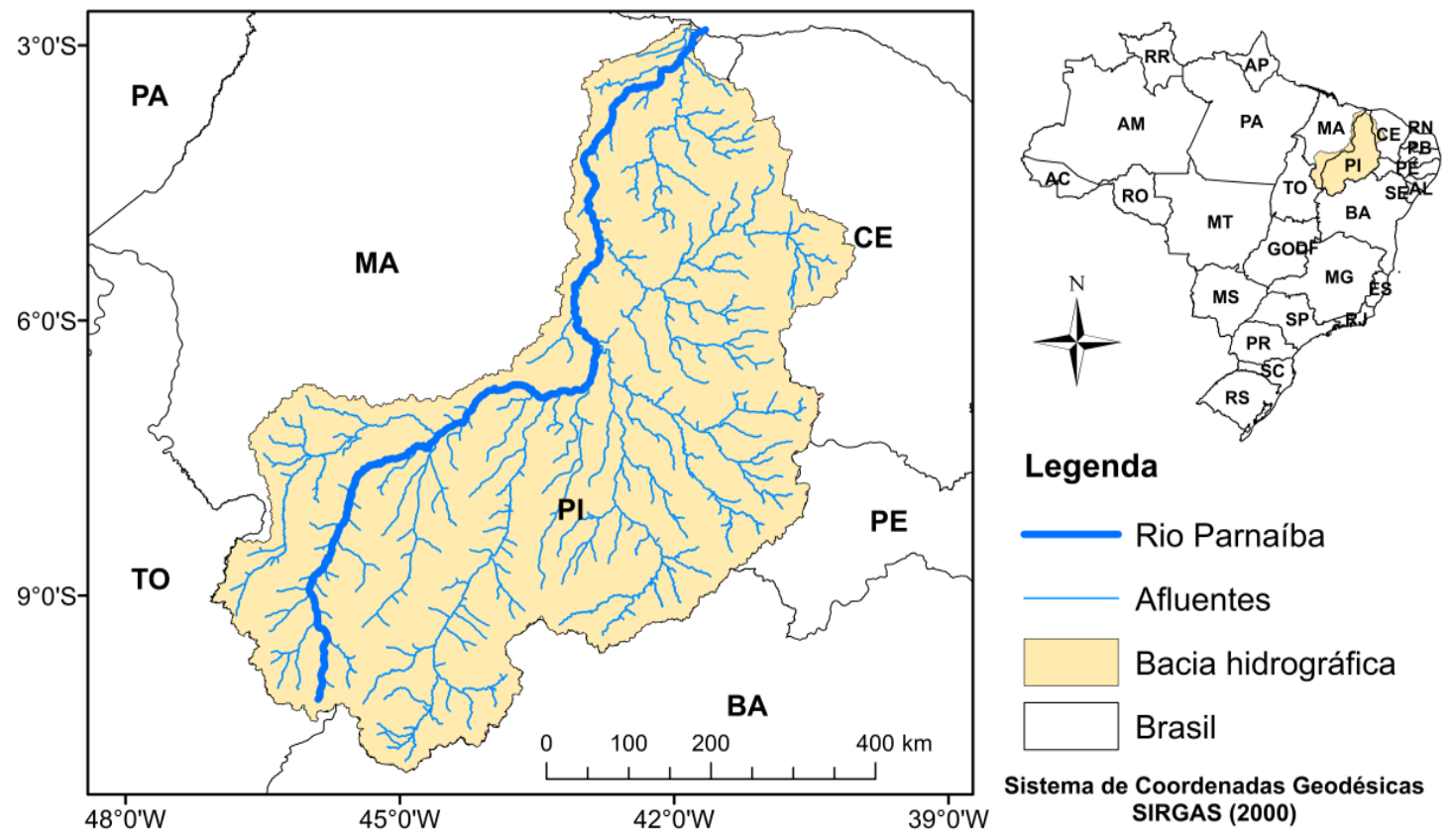

Legenda

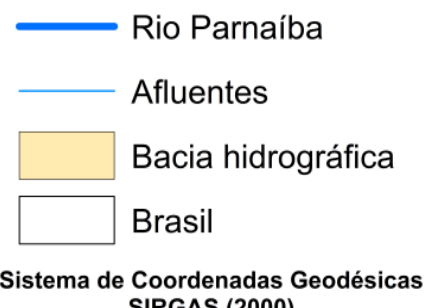

Fonte: Os autores (2016)

\section{Dados}

\section{Modelo Digital de Elevação}

Os Modelos Digitais de Elevação (MDE) utilizados para delimitação da região da BHRG foram obtidos a partir de dados SRTM (Shuttle Radar TopographyMission) segundo produtos refinados por Miranda (2005). Os dados de elevação serão utilizados nesse estudo em conjunto com o software Arcgis para delimitação da BHRP e obtenção de diversos mapas.

\section{Produtos Modis -Terra}

As imagens MODIS são adquiridas no formato HDF (Hierarchical Data Format) e pode-se utilizar o software MRT (MODIS Reprojection Tool) para convertê-las no formato GeoTIFF, para posterior processamento com o programa Erdas. A área de estudo está inserida nos tiles h13v09, h14v09, h13v10, h14v10.

Foram utilizadas imagens do dia 18 de junho de 2005 e 18 de junho de 2015, o critério de seleção associado à escolha desse mês está relacionado à menor presença de nuvens e falhas nas imagens.

A Tabela 1 descreve os produtos MODIS que foram utilizados no presente estudo, com os fatores de correção (multiplicativo e/ou adicional) que são empregados para converter 
os valores originais em dados de temperatura $(\mathrm{K})$, emissividade (adimensional), reflectância (adimensional), dentre outros.

Tabela 1 - Descrição dos produtos MODIS utilizados

\begin{tabular}{|c|c|c|c|c|c|}
\hline Produto & Descrição & $\begin{array}{c}\text { Fator } \\
\text { Multiplicativo }\end{array}$ & $\begin{array}{c}\text { Fator } \\
\text { adicional }\end{array}$ & $\begin{array}{l}\text { Resolução } \\
\text { (espacial e } \\
\text { temporal) }\end{array}$ & Unidades \\
\hline MOD11A2 & $\begin{array}{c}\text { Temperatura } \\
\text { da superfície } \\
\text { Emissividade } \\
\text { das bandas } 31 \\
\text { e } 32 \\
\text { Hora da } \\
\text { passagem do } \\
\text { satélite }\end{array}$ & $\begin{array}{c}0,002 \\
0,1\end{array}$ & 0,490 & $\begin{array}{c}1000 \mathrm{~m} \\
8 \text { dias }\end{array}$ & $\begin{array}{c}\text { Kelvin } \\
\text { Adimensional } \\
\text { Hora }\end{array}$ \\
\hline MOD09A1 & $\begin{array}{c}\text { Refletância da } \\
\text { superfície } \\
\text { Ângulo } \\
\text { zenital solar } \\
\text { Dia de ordem } \\
\text { do ano (DOA) }\end{array}$ & 0,0001 & - & $\begin{array}{l}500 \mathrm{~m} \\
8 \text { dias } \\
1000 \mathrm{~m} \\
8 \text { dias } \\
1000 \mathrm{~m} \\
8 \text { dias }\end{array}$ & $\begin{array}{l}\text { Adimensional } \\
\text { Grau } \\
\text { Dia Juliano }\end{array}$ \\
\hline
\end{tabular}

Fonte: http://modis.gsfc.nasa.gov/

\section{Métodos}

Variáveis caracterizadoras dos aspectos físicos da bacia hidrográfica

O software Arcgispermitiu realizar a obtenção da maioria dos parâmetros físicos da bacia hidrográfica: área de drenagem, perímetro, comprimento do rio principal, comprimento do talvegue, comprimento total dos cursos d'água e comprimento axial da bacia hidrográfica.

O coeficiente de compacidade de uma bacia hidrográfica, $k c$, é um índice que informa a susceptibilidade da ocorrência de inundações nas partes baixas da bacia hidrográfica. É definido pela relação entre o perímetro da bacia hidrográfica e o perímetro do círculo de igual área (VILLELA; MATTOS, 1975). O $k c$ é dado por:

$$
k_{c}=0,28 \frac{P}{\sqrt{A}}
$$

Em que $A$ corresponde à área da bacia e $P$ o perímetro da bacia hidrográfica. 
O fator de forma $(k f)$ corresponde à relação entre a área de uma bacia hidrográfica e o quadrado de seu comprimento axial, medido ao longo do curso de água da desembocadura à cabeceira mais distante (GARCEZ; ALVAREZ, 1988).Esse fator podeser obtido por:

$$
k_{f}=\frac{A}{L^{2}}
$$

Em que $A$ corresponde à área da bacia e $L$ o seu comprimento axial.

O ordenamento dos canais da bacia foi realizado conforme Strahler (1964). Nesse sistema os canais que não apresentam tributários são de primeira ordem. A confluência de dois canais de primeira ordem origina um de segunda ordem e na confluência de dois canais de segunda ordem originam um de terceira ordem e assim sucessivamente. Quando dois rios de ordens hierárquicas diferentes juntam-se, prevalece a maior ordem.

A densidade de drenagem de uma bacia hidrográfica é obtida dividindo-se o comprimento total dos cursos de água efêmeros, intermitentes e perenes pela a área total da bacia (GARCEZ; ALVAREZ, 1988).

A extensão média do escoamento superficial será representada matematicamente por (VILLELA; MATTOS, 1975):

$$
l=\frac{A}{4 L}
$$

Em que $L$ é o comprimento do rio principal e $A$ corresponde à área de drenagem da bacia hidrográfica.

O índice de sinuosidade de um curso d'água (Is) é definido pela relação entre o comprimento do rio principal e a distância vetorial entre os pontos extremos do canal principal (ALVES; CASTRO, 2003), dado por:

$$
\text { Is }=\frac{L}{d v}
$$

Sendo $d v$ distância vetorial entre os pontos extremos do canal principal.

A declividade de álveo deverá ser definida dividindo-se a diferença total de elevação do leito pela extensão horizontal do curso d'água entre esses dois pontos conforme Villela e Mattos (1975). A declividade e relevo da bacia hidrográfica foram obtidas a partir do MDE e do programa ArcGis, através da extensão SpatialAnalyst. 
Variáveis Importantes para o Cômputo do Saldo de Radiação Albedo da Superfície

O albedo é definido pela razão entre a radiação solar global refletida por cada pixel e a radiação solar incidente no mesmo, em todo o domínio da radiação de onda curta $(0,3$ a 3,0 $\mu \mathrm{m})$. Para a sua determinação foram utilizados dois métodos: um proposto por Liang (2000) e outro por Tasumi et al. (2008).O albedo segundo o método Liang (2000) - $\alpha_{L}$ fundamenta-se na equação:

$$
\alpha_{L}=0,160 \cdot \rho_{1}+0,291 \cdot \rho_{2}+0,243 \cdot \rho_{3}+0,116 \cdot \rho_{4}+0,112 \cdot \rho_{5}+0,081 \rho_{7}-0,0015
$$

em que $\rho_{1}, \rho_{2}, \ldots, \rho_{7}$, representam as refletâncias monocromáticas relativas a cada uma das sete bandas espectrais do MODIS, distribuídas por meio do produto MOD09A1.

Para o cômputo do albedo conforme a metodologia descrita em Tasumi et al. (2008) $\alpha_{T}$, utilizou-se a equação:

$$
\alpha_{T}=\sum_{b=1}^{n}\left[\rho_{s, b} w_{b}\right]
$$

em que os pesos $w_{b}$ são os coeficientes de ponderação que representam a fração da radiação solar que ocorre no intervalo espectral da banda específica, constantes na Tabela 1 ; $n$ é o número de bandas correspondente e $\rho_{s, b}$ é a refletância espectral à superfície, obtida do produto MOD09A1.

Tabela 2 - Coeficientes de ponderação $\left(W_{b}\right)$ da Equação (6), para uso em imagens MODIS

\begin{tabular}{cccccccc}
\hline \multirow{2}{*}{ Coeficiente } & Banda & Banda & Banda & Banda & Banda & Banda & Banda \\
& 1 & 2 & 3 & 4 & 5 & 6 & 7 \\
\hline$W_{b}$ & 0,215 & 0,215 & 0,242 & 0,129 & 0,101 & 0,062 & 0,036 \\
\hline
\end{tabular}

Fonte: Tasumi et al. (2008)

\section{SALDO DE RADIAÇÃO}

O saldo de radiação foiestimado com base na Equação (7), de duas diferentes formas, que diferem quanto ao método de cômputo do albedo da superfície, da radiação de onda curta incidente e da radiação de onda longa incidente. Convencionou-se denominá-los de saldo SEBAL (RnS) $e$ saldo METRIC (RnM), cuja forma geral é dada por: 


$$
R n=R s(1-\alpha)+R_{L \downarrow}-R_{L \uparrow}-\left(1-\varepsilon_{o}\right) R_{L \downarrow}
$$

em que Rs $\left(\mathrm{Wm}^{-2}\right)$ é a radiação de onda curta incidente, $\alpha$ (adimensional) é o albedo da superfície; $R_{L \downarrow}\left(\mathrm{Wm}^{-2}\right)$ é a radiação de onda longa incidente, proveniente da atmosfera; $R_{L \uparrow}\left(\mathrm{Wm}^{-2}\right)$ é a radiação de onda longa emitida por cada pixel; e $\left(1-\varepsilon_{0}\right) R_{L \downarrow}\left(\mathrm{Wm}^{-2}\right)$ representa a fração de radiação de onda longa incidente que é refletida pela superfície e $\varepsilon_{0}$ é a emissividade da superfície (adimensional). O termo $\alpha \mathrm{Rs}\left(\mathrm{Wm}^{-2}\right)$ representa o fluxo de radiação de onda curta refletido pela superfície.

\section{SALDO SEBAL}

A radiação de onda curta incidente $\left(R_{S \downarrow}\right)$ corresponde ao fluxo de radiação solar (direta e difusa) que atinge a superfície terrestre e que para condição de céu claro pode ser obtida, segundo Allen et al. (2007), por:

$$
R_{S \downarrow}=\frac{S_{0} \cdot \cos \theta_{z} \cdot \tau_{s w}}{d^{2}}
$$

em que $S_{0}$ é a constante solar (1367 $\left.\mathrm{W} \mathrm{m}^{-2}\right) ; \theta_{z}$ é ângulo zenital solar, em graus, obtido do produto MOD09A1; $\mathrm{d}^{2}$ = quadrado da distância relativa Terra-Sol, obtido segundo (DUFFIE; BECKMAN,1991):

$$
d^{2}=\frac{1}{1+0,033 \cos (D S A 2 \pi / 365)}
$$

em que DSA é o dia sequencial do ano. Já a transmissividade atmosférica $\left(\tau_{s w}\right)$ será estimada de acordo com Allen et al. (1998):

$\tau_{s w}=0,75+2 \cdot 10^{-5} z$

em que $\mathrm{z}$ representa a altitude de cada pixel da imagem que será obtida do MDE.

A radiação de onda longa incidente, emitida pela atmosfera na direção da superfície $\mathrm{R}_{\mathrm{L} \downarrow}\left(\mathrm{W} \mathrm{m}^{-2}\right)$, será dada através da equação de Stefan-Boltzmann:

$$
R_{L \downarrow}=\varepsilon_{a} \sigma T_{a}^{4}
$$

em que $\mathrm{T}_{\mathrm{a}}$ é a temperatura do ar próximo à superfície, $\sigma$ é a constante de Stefan-Boltzmann $\left(\sigma=5,67 \times 10^{-8} \mathrm{~W} \mathrm{~m}^{-2} \mathrm{~K}^{-4}\right)$ e $\varepsilon_{\mathrm{a}}$ é a emissividade atmosférica, calculada segundo modelo proposto por Bastiaanssen et al. (1998), qual seja: 


$$
\varepsilon_{a}=a\left(-\ln \tau_{S W}\right)^{b}
$$

em que $a$ e $b$ são coeficientes de calibração cujos valores, de acordo com Bastiaanssen et al. (1998), são respectivamente iguais a 1,08 e 0,265.

A radiação de onda longa emitida por cada pixel - $\mathrm{R}_{\mathrm{L} \uparrow}\left(\mathrm{W} \mathrm{m}^{-2}\right)$ deverá ser calculada também segundo a equação de Stefan-Boltzmann:

$$
R_{L \uparrow}=\varepsilon_{0} \sigma T_{S}^{4}
$$

em que $\varepsilon_{0}$ é a emissividade de cada pixel e Ts (K) é a temperatura da superfície, obtidos do produto MOD11A2. A emissividade da superfície será considerada igual à média aritmética das emissividades das bandas 31 e 32, conforme proposto por Bisht et al. (2005).

O albedo utilizado para computar o RnS foi o albedo Liang.

\section{Saldo METRIC}

A radiação de onda curta foi calculada através da Equação 8, sendo a transmissividade estimada conforme Allen et al. (2007) por:

$$
\tau_{s w}=0,35+0,627 \exp \left[\frac{-0,00146 P}{K_{t} \cos \theta_{z}}-0,075\left(\frac{W}{\cos \theta_{z}}\right)^{0,4}\right]
$$

em que $\theta_{z}$ é o ângulo zenital solar, obtido do produto MOD09A1;P é a pressão atmosférica média em $k P a ; k_{t}$ é o coeficiente de turbidez da atmosfera, sendo $\mathrm{k}_{\mathrm{t}}=1$ para céu claro e $\mathrm{k}_{\mathrm{t}}=0,5$ para turbidez extrema (ALLEN, 1996); $W$ é a água precipitável (mm), calculada de acordo com equação proposta por Garrison e Adler (1990):

$$
W=0,14 e_{a} P_{\text {air }}+2.1
$$

A pressão atmosférica poderá ser obtida conforme (ASCE-EWRI, 2005):

$$
P=101,3\left(\frac{293-0,0065 z}{293}\right)^{5,26}
$$

em que $e_{a}$ é a pressão de vapor próximo a superfície (KPa) e W está em milímetros, z (m) é a altitude, representada pelo MDE.

A radiação de onda longa emitida por cada pixel foi calculada pela Equação 13, enquanto que a radiação de onda longa incidente foi estimada com a Equação 11, sendo os coeficientes $a$ e $b$ da Equação 12 utilizados conforme Allen et al. (2002), que são respectivamente 0,85 e 0,09 . O albedo utilizado nesta metodologia foi o $\alpha_{T}$. 


\section{RESULTADOS E DISCUSSÃO}

\section{Características físicas da BHRP}

O coeficiente de compacidade e o fator de forma são índices relacionados à forma da bacia hidrográfica, apresentaram os valores 2,89 e 0,37 respectivamente. Estes valores indicam que a área da bacia não é suscetível a enchentes em condições normais de precipitação conforme Villela e Mattos (1975).Desta forma, há uma indicação de que a BHRP possui formato alongado e estreito. Pois, em bacias com formato circular, há maiores possibilidades de chuvas intensas ocorrerem simultaneamente em toda a sua extensão, concentrando grande volume de água no rio principal (CARDOSO et al., 2006).

Segundo Milani e Canali (2000), a densidade de drenagem reflete a propriedade de transmissibilidade do terreno e, consequentemente, a suscetibilidade a erosão. Assim, a densidade de drenagem encontrada na BHRP foi de $0,77 \mathrm{~km} / \mathrm{km}^{2}$, indicandobaixa capacidade de drenageme elevada transmissibilidade, ou seja, apresenta um bom grau de infiltração.De acordo com a hierarquia de Strahler (1964) o sistema de drenagem possui ramificação de sétima ordem.

A sinuosidade do curso d'água é de 1,44, este valor indica que o rio Parnaíba apresenta formas transicionais, regulares e irregulares em seu percurso, conforme Alves e Castro (2003). A extensão média do escoamento superficial é de aproximadamente $87 \mathrm{~km}$. Este índice indica a distância média em que a água teria que escoar sobre os terrenos de uma bacia, caso o escoamento se desse em linha reta, de onde a chuva caiu até o curso d'água mais próximo (VILLELA; MATTOS, 1975).

Tabela 3 - Índices físicos da BHRP

\begin{tabular}{lc}
\hline \multicolumn{1}{c}{ Índices } & Valores \\
\hline Área da bacia hidrográfica $\left(\mathrm{km}^{2}\right)$ & 331775,00 \\
Perímetro da bacia hidrográfica $(\mathrm{km})$ & 5945,44 \\
Comprimento do rio principal $(\mathrm{km})$ & 1371,00 \\
Coeficiente de compacidade & 2,89 \\
Fator de forma & 0,37 \\
Densidade de drenagem $\left(\mathrm{km} / \mathrm{km}^{2}\right)$ & 0,77 \\
Extensão média do escoamento superficial $(\mathrm{km})$ & 87,31 \\
Sinuosidade do curso d'água & 1,44 \\
\hline
\end{tabular}

Fonte: Os autores (2016)

A Figura 2 ilustra a distribuição das altitudes na bacia. A altitude média é de 354,60 $\mathrm{m}$, enquanto a amplitude altimétrica, diferença entre as cotas máxima e mínima é de $1005 \mathrm{~m}$. 
As regiões de maior elevação da bacia hidrográfica se concentram na parte nordeste, onde se situa a Serra de Ibiapaba no estado do Ceará, e sudoeste da bacia correspondendo à região de nascentes. As menores altimetrias foram observadas na região dos lençóis maranhenses, a noroeste da bacia, e na foz do Parnaíba, ou seja, no delta do Parnaíba.

A definição da amplitude altimétrica é essencial para a caracterização física da bacia, pois esta influencia na temperatura, precipitação e evaporação. Na tabela 4, verificam-se as faixas hipsométricas da região. Observa-se, nesta tabela, que $81,4 \%$ da região da $\mathrm{BH}$ correspondem a uma altitude inferior a $500 \mathrm{~m}$. As faixas que apresentaram maior concentração de área hidrográfica estão associadas às altitudes entre 300 e 500m e correspondem a 43,7\% da área total.

Figura 2 - Mapa hipsométrico da região em estudo

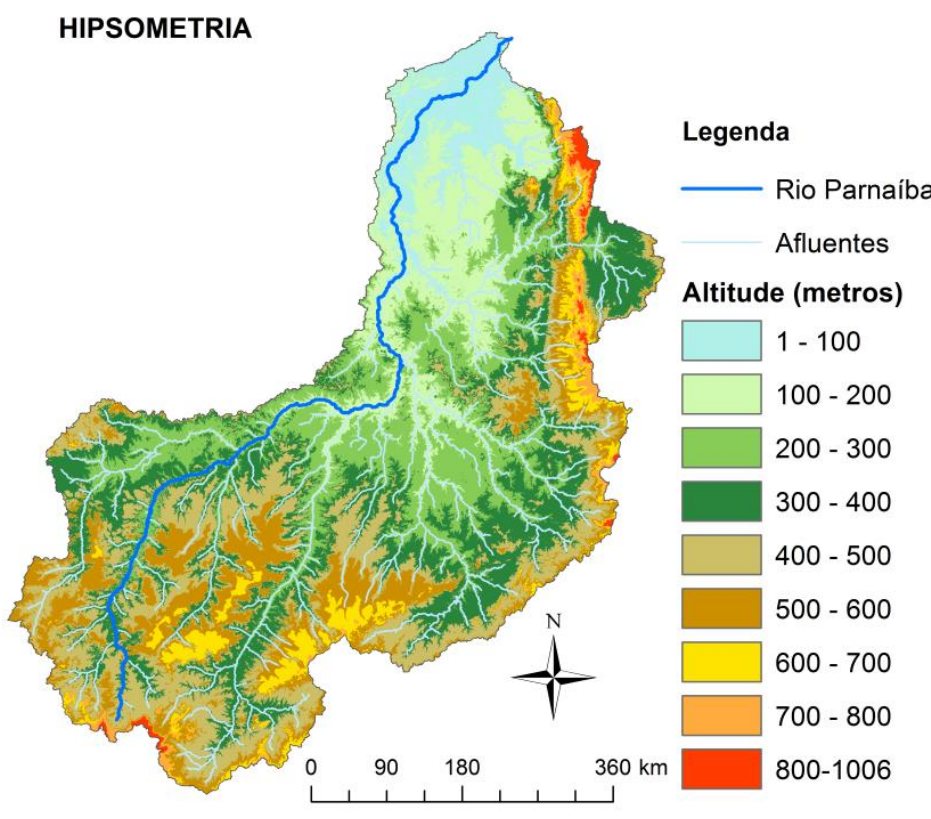

Fonte: Os autores (2016)

Tabela 4 - Faixas hipsométricas da BHRP

\begin{tabular}{cccc}
\hline $\begin{array}{c}\text { Altitude } \\
(\mathrm{m})\end{array}$ & $\begin{array}{c}\text { Área } \\
\left(\mathrm{km}^{2}\right)\end{array}$ & $\begin{array}{c}\text { Percentual } \\
\text { por classe }\end{array}$ & $\begin{array}{c}\text { Percentual } \\
\text { acumulado }\end{array}$ \\
\hline $1-100$ & 20152,5 & 6,1 & 6,1 \\
$100-200$ & 42214,6 & 12,7 & 18,8 \\
$200-300$ & 62485,5 & 18,8 & 37,6 \\
$300-400$ & 76421,6 & 23,0 & 60,7 \\
$400-500$ & 68778,0 & 20,7 & 81,4 \\
$500-600$ & 40716,5 & 12,3 & 93,7 \\
$600-700$ & 14151,0 & 4,3 & 97,9 \\
\hline
\end{tabular}




\begin{tabular}{cccc}
$700-800$ & 4659,4 & 1,4 & 99,3 \\
Fonte: Os autores (2016) & 2194,1 & 0,7 & 100,0 \\
\hline
\end{tabular}

O mapa de declividade é uma forma de representação quantitativa do comportamento espacial do relevo (OLIVEIRA; BORSATO, 2011). A maior parte da região da BHRP $(82,9 \%)$ corresponde aos tipos de declividade plana e suave ondulada, Tabela 5 e Figura 3. As declividades superiores a $20 \%$ correspondem a escassas áreas na região da bacia (cerca de $4 \%)$. A declividade de álveo $(\mathrm{m} / \mathrm{m})$ é de $0,44 \mathrm{~m} / \mathrm{km}$. A declividade média é de $4,9 \%$, este fato revela que a bacia possui em média baixa declividade o que resulta numa redução dos picos de enchentes devido à baixa velocidade do escoamento (VILLELA; MATTOS, 1975).

Figura 3 - Mapa da declividade da região em estudo

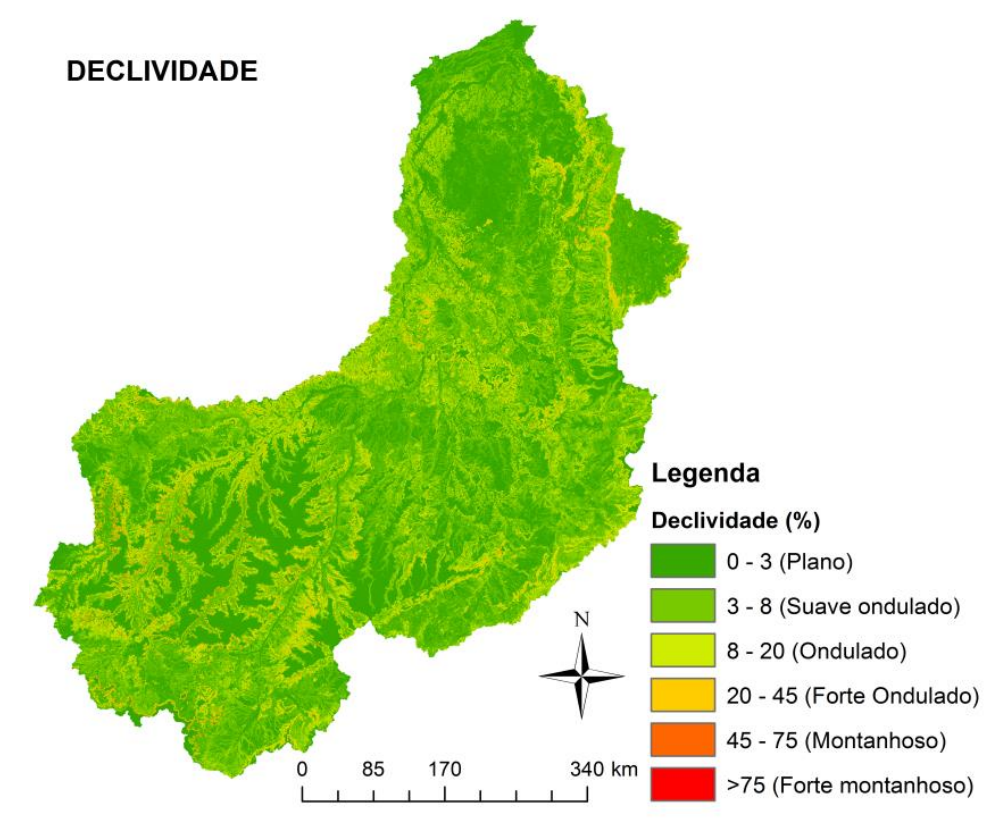

Fonte: Os autores (2016)

Tabela 5 - Faixas de declividade da BH do rio Parnaíba

\begin{tabular}{lccc}
\hline $\begin{array}{c}\text { Tipos de declividade } \\
(\%)\end{array}$ & $\begin{array}{c}\text { Área } \\
\left(\mathrm{km}^{2}\right)\end{array}$ & $\begin{array}{c}\text { Percentual } \\
\text { por classe }\end{array}$ & $\begin{array}{c}\text { Percentual } \\
\text { acumulado }\end{array}$ \\
\hline Plano (0 - 3) & 160940,0 & 48,5 & 48,5 \\
Suave Ondulado (3 - 8) & 114118,5 & 34,4 & 82,9 \\
Ondulado (8 - 20) & 43894,2 & 13,2 & 96,1 \\
Forte Ondulado (20 - 45) & 11818,8 & 3,6 & 99,7 \\
Montanhoso (45 - 75) & 982,4 & 0,3 & 100,0 \\
Forte Montanhoso (>75) & 16,0 & 0,005 & 100,0 \\
\hline Os autores (2016) & & &
\end{tabular}




\section{Características biofísicase saldo de radiação da BHRP}

Ao realizar uma análise comparativa entre os métodos Liang e Tasumi, foi verificado no ano de 2005, valores médios de 0,13(Liang) e 0,12(Tasumi), conforme Tabela 6. No ano de 2015, essas médias foram levemente superiores ao ano de 2005, verificou-se 0,14 (Liang) e 0,13 (Tasumi). Assim, para ambos os períodos estudados, os valores médios do albedo Liangsão levemente superiores às médias do albedo Tasumi. Os valores máximos para ambos os métodos foram muito semelhantes, no entanto, os valores mínimos apresentaram maior variação, de acordo com a Tabela 6.

A análise dos dois métodos é uma forma de validação da metodologia. Na ausência de dados de campo, a discrepância entre os resultados dá um indicativo da confiabilidade da metodologia, visto que os cômputos são baseados na refletividade de cada banda, variando apenas os pesos atribuídos para cada banda nas duas formas de cômputo, os quais resultam da calibração empregada em cada método. Dessa maneira, pode-se concluir que houve êxito das estimativas, haja vista a proximidade entre os valores obtidos, considerando a natureza das variáveis empregadas. Santos (2011) em estudo utilizando o sensor MODIS, em área de Cerrado, no estado de São Paulo, obteve albedo médio igual a 0,12 para a metodologia Liang e 0,11 para a metodologia Tasumi, enquanto as medidas de campo apresentaram um valor médio de 0,13. Já Santos (2015) obteve para o albedo Liang o valor médio de 0,13 para uma área de Caatinga em recuperação e 0,19 para uma área de Caatinga degradada, enquanto o albedo Tasumi foi de 0,12 e 0,18, respectivamente, para as mesmas áreas. As medidas de campo para o mesmo estudo corresponderam aos valores médios de 0,12 e 0,20 para as áreas citadas, respectivamente.

Na Figura 4 é possível notar predominância de áreas com albedo inferior a 0,16, esse fato revela que a região apresenta baixa refletividade. É possível notara represa de Boa esperança, em todas as imagens, na parte centro-oeste da bacia. Para ambos os métodos, a cena de 2015 apresentou leve aumento nos valores do albedo observados ao longo de toda a bacia em relação à cena 2005. A ampliação das áreas correspondentes à faixa de valores entre 0,18 e 0,22 destacou-se ao sudoeste e centro-norte da bacia, regiões de predominância da vegetação Savana e Caatinga, respectivamente (Figura 5).

Os valores do albedo observados para Caatinga corroboram com outros estudos como o de Bezerra et al (2014) em que utilizando seis imagens orbitais do TM/ LANDSAT 5 no período de 2007 a 2010, em áreas com cobertura vegetal de Caatinga mais densa no período de estiagem apresentaram valores entre 0,15 e 0,20, devido à perda da parte aérea do dossel 
foliar. Já para área de Caatinga próxima a cidade de Lagoa Grande no estado de Pernambuco, Teixeira et al. (2008) encontraram para o albedo, a partir de medidas de campo, valores mínimos de 0,11 e máximos de 0,17 nos anos de 2004 e 2005.

Figura 4 - Albedo da superfície estimado para a BHRP

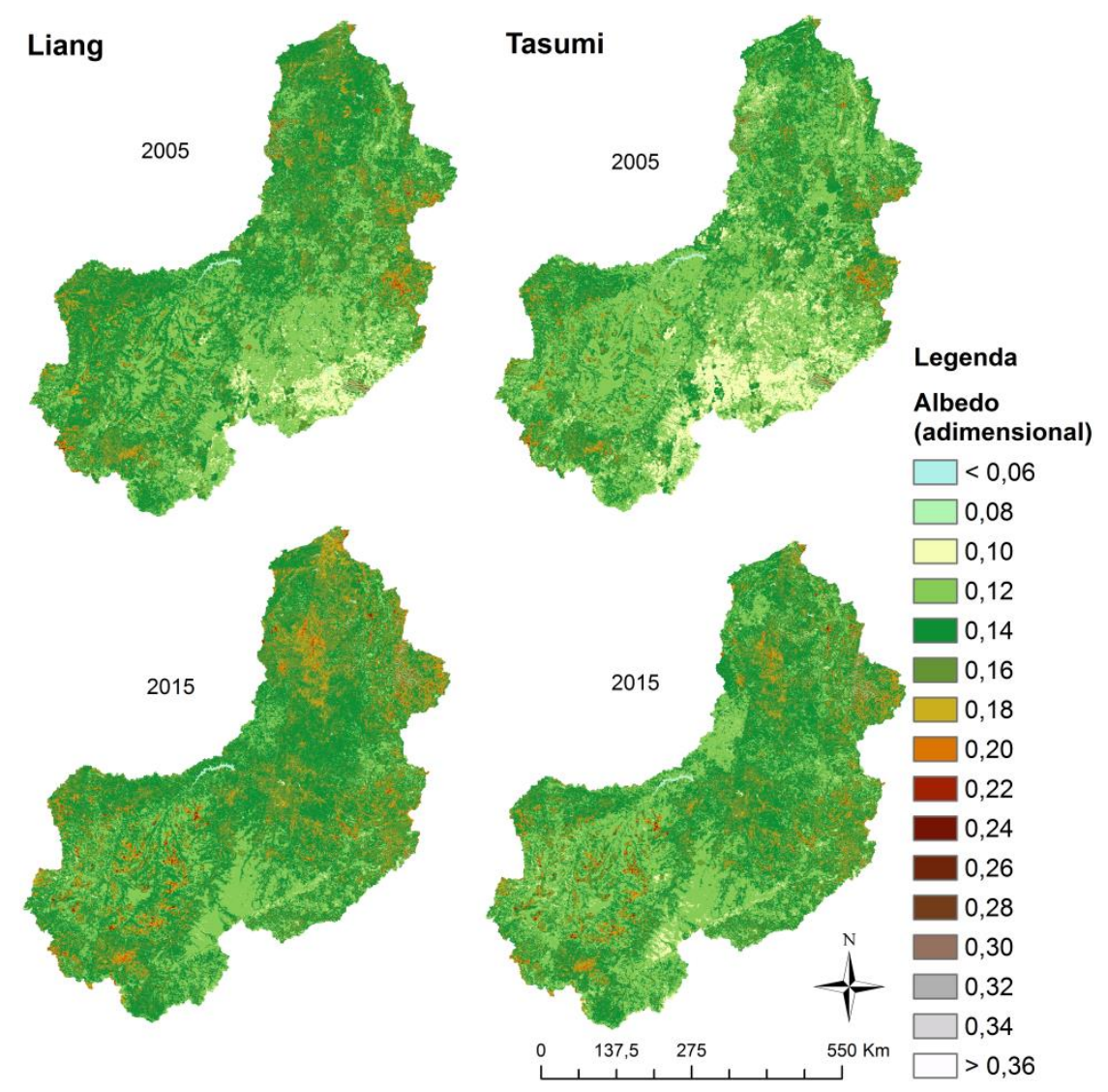

Fonte: Os autores (2016) 
Figura 5 - Tipos de vegetação da BHRP.
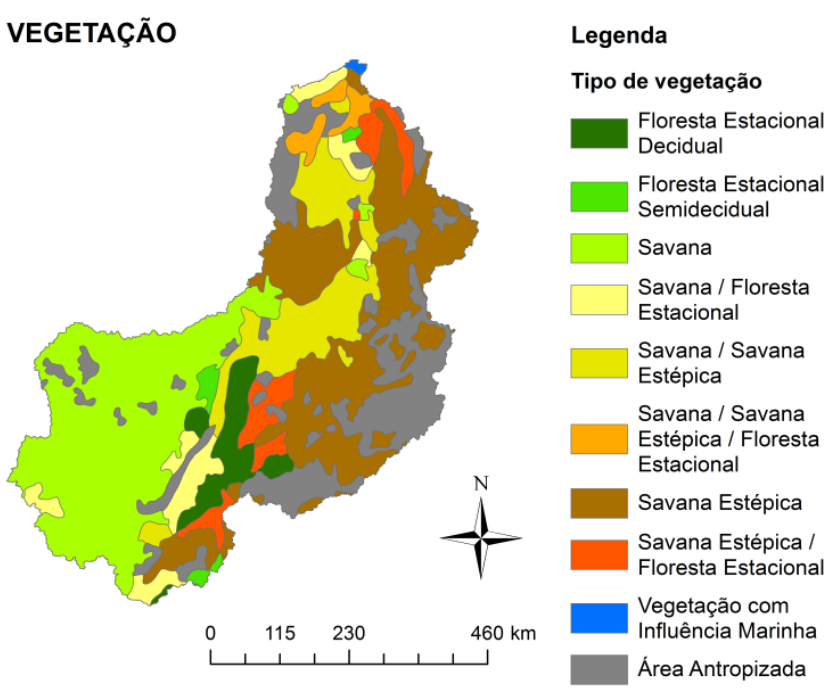

Fonte: Adaptado doIBGE (2013)

Na cena 2005, para ambos os métodos, a parte sudeste da bacia correspondente à área antropizada (Figura 5) apresentou baixos valores de albedo (em torno de 0,10), com maior destaque para Tasumi, pois apresentou maior área com menores valores de albedo. Valores esses que, no ano de 2015 apresentaram um aumento, situando-se por volta de 0,12 a 0,14. A princípio esse resultado poderia ser compatível com um solo mais descoberto devido à perda ou substituição de vegetação, que resultaria em maior refletividade da superfície. No entanto, faz-se necessário uma análise das condições hídricas para os dois períodos em estudo. Sabendo-se que, os totais pluviométricos foram maiores para o ano de 2005 em comparação com 2015 (Figura 6) para o mesmo período, não dá para concluir se houve degradação, já que a maior disponibilidade de água no solo tende a diminuir o valor do albedo.

Figura 6 - Totais pluviométricos (Janeiro a maio) de municípios pertencentes à BHRP.

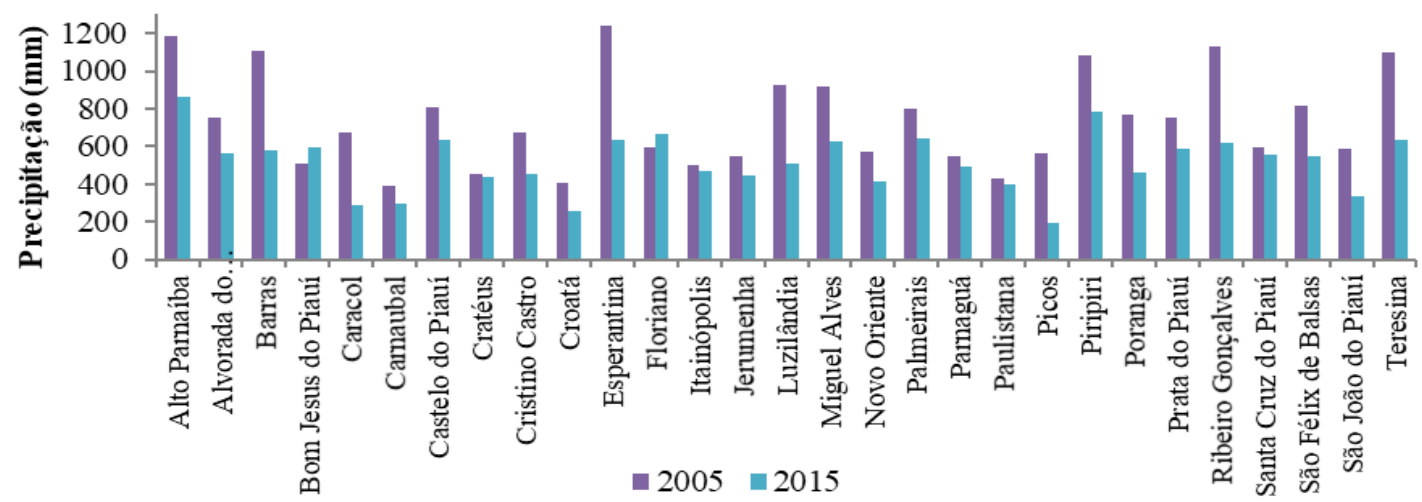

Fonte: ANA (2016) e INMET (2016) 
Os maiores valores de NDVI podem ser verificados na região noroeste da bacia para ambos os anos considerados, conforme Figura 7. De acordo com Brasil (2006), nessa região estão presentes os maiores índices de precipitação média anual, sendo assim justificados os altos valores de NDVI. Ainda, segundo esses autores, a maior parte dessa área é composta pelo bioma Ecótonos Caatinga-Amazônia.Dessa forma a resposta da vegetaçãoa ocorrência das chuvas é bastante rápida.

A cena de 2005, quando comparada a 2015, apresentou maior área com índices acima de 0,70, compatível com os resultados encontrados para o albedo, que apresentou menores valores em 2005, comprovando o comportamento inverso entre essas duas variáveis. Esse fato está associado à pluviometria na região hidrográfica, pois os totais pluviométricos do primeiro semestre de 2005 foram superiores aos totais de 2015 para o mesmo período de tempo. Podem-se notar, também, como previsto na literatura, os valores negativos de NDVI para corpos hídricos. Os valores médios de NDVI corresponderam a 0,63 na cena de 2005 e 0,56 na cena de 2015, Tabela 6. Os menores valores de NDVI foram observados na parte leste da bacia, esse fato pode estar associado ao fato dessa região corresponder a uma área antropizada e de vegetação Caatinga, conforme Figura 5. Para área de Caatinga densa Bezerra et al. (2014) encontraram máximos valores de NDVI variando entre 0,6 e 0,8, para os meses de julho de 2008 e julho de 2009. Os autores justificam o fato supondo ser a precipitação o principal fator de modificações da umidade no solo. Na mesorregião do Agreste paraibano, Santos (2015) obteve para o mês de junho de 2013, valores de NDVI, em sua maior parte, superiores a 0,75 . O fato provavelmente se deve ao maior valor de precipitação para a região nesse período (Figura 6), onde predomina a Caatinga. 


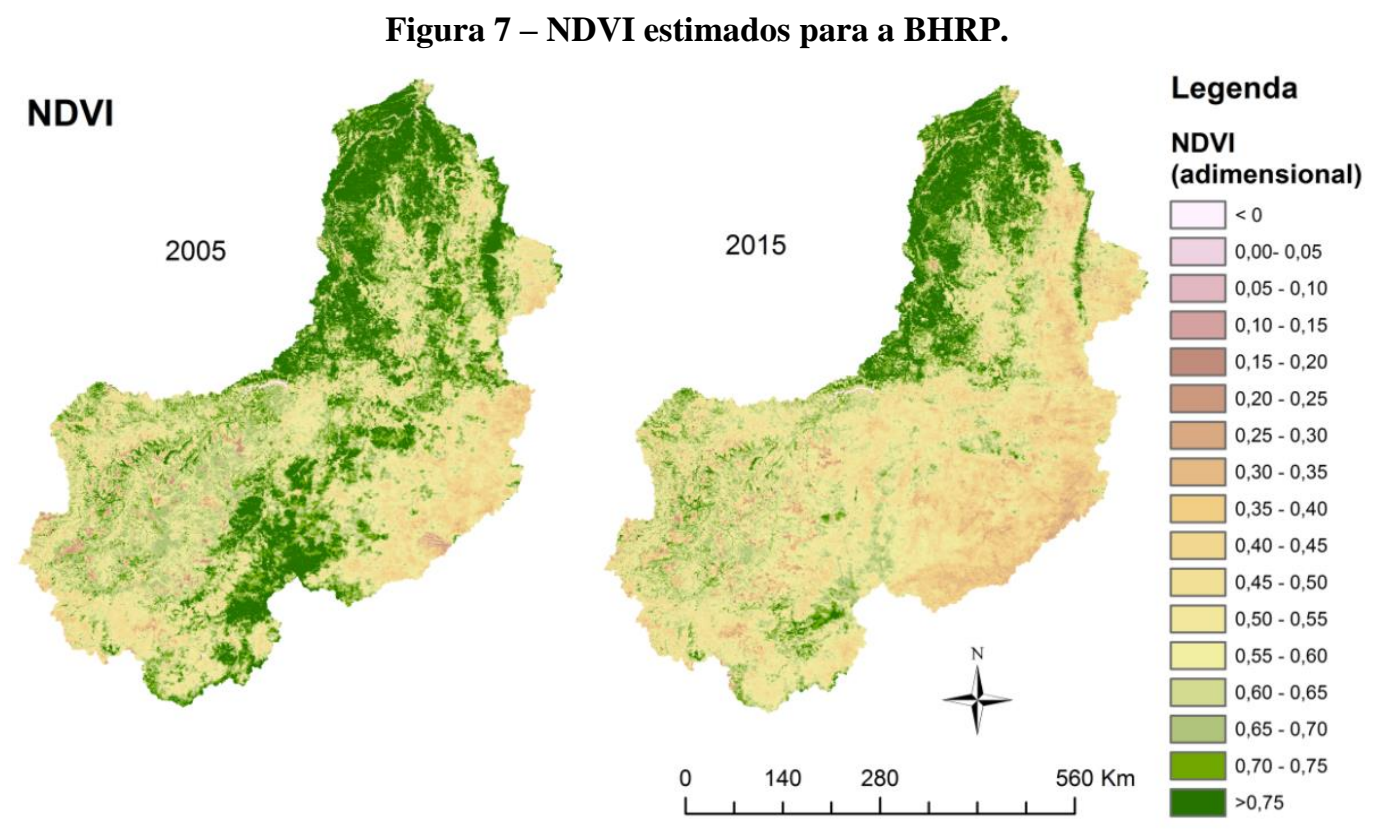

Fonte: Os autores (2016)

Na Figura 8 é possível identificar maior extensão de áreas com temperaturas mais elevadas na cena de 2015. A temperatura média para a cena de $2015(304,46 \mathrm{~K})$ foi superior à cena de 2005 (302,6 K), Tabela 6. Esse resultado representa uma boa confiabilidade na utilização do MOD11A2, visto que apesar de ser um produto derivado exclusivamente de dados orbitais, parece representar bem as condições da área, visto que no ano de 2015 a temperatura apresentou-se superior, corroborando com a condição de menor precipitação que o ano de 2005, Figura 6. As áreas com valores superiores a $308 \mathrm{~K}$ destacaram-se na região central da bacia. Em contrapartida, as menores temperaturas foram observadas, para ambas as cenas, com maior extensão na parte noroeste da região em estudo. Resultado esperado, haja vista nessa mesma porção obtiveram-se os maiores valores de NDVI. Nas áreas em que o NDVI é maior se tem uma redução na temperatura da superfície devido a maior cobertura do solo. Essas duas variáveis devem apresentar uma correlação negativa, como demonstrada em Santos (2015). Fato também comprovado ainda, na cena de 2005, o sudeste da bacia apresentou regiões com temperaturas inferiores à média. Fato provavelmente associado à cobertura do solo nessa região, pois em sua maior parte é composta por Caatinga, que após o período chuvoso, apresenta um rápido aumento da densidade da vegetação e consequente cobertura do solo. Ainda, a região da Serra de Ibiapaba, nordeste da bacia, apresentou temperaturas amenas devido à influência da orografia local, essa região destacou-se com altos valores de NDVI. 
Figura 8 - Temperatura da superfície (K) estimada para a região da BHRP.

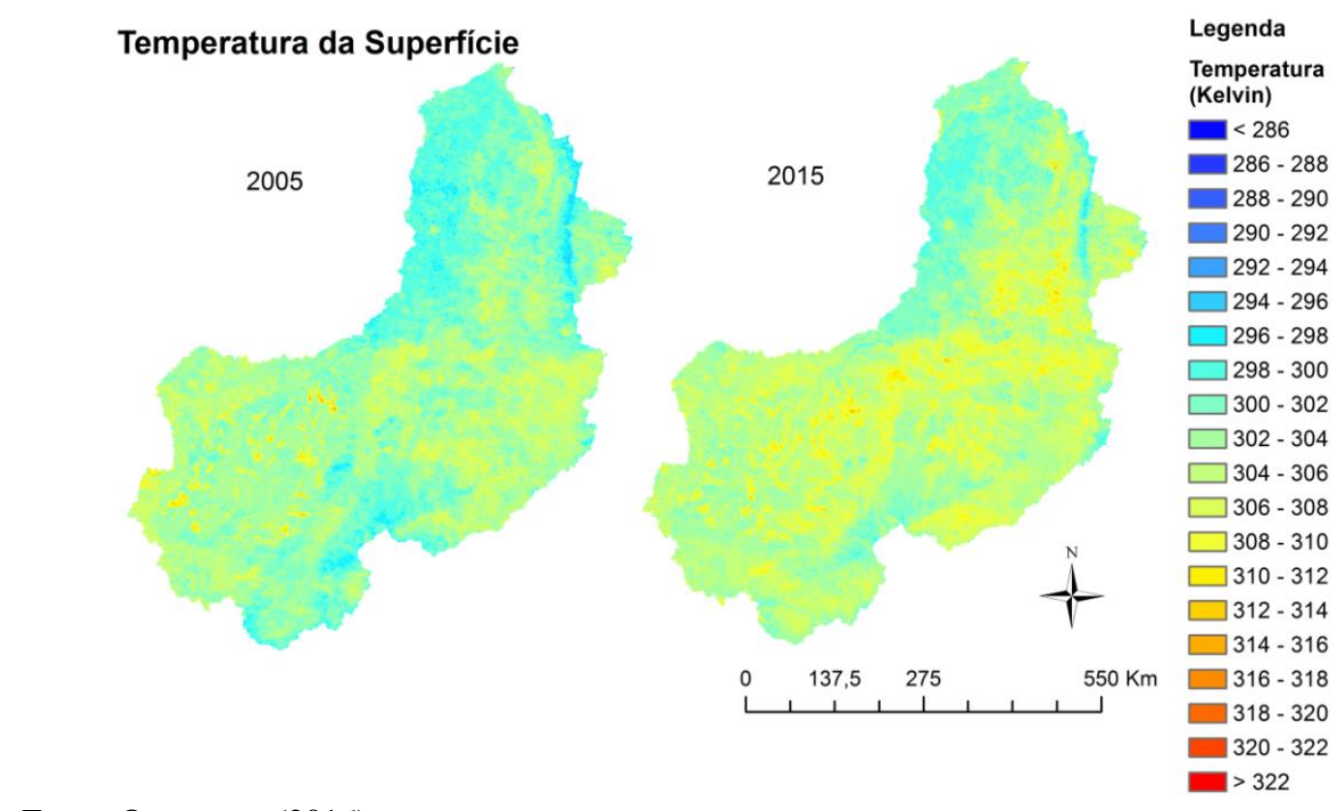

Fonte: Os autores (2016)

O saldo SEBAL apresentou maiores valores médios quando comparados ao METRIC, conforme Tabela 6. Fato provavelmente relacionado à utilização da umidade relativa no cômputo da transmissividade atmosférica na segunda metodologia, enquanto no método SEBAL a transmissividade estimada varia apenas em função da altitude de cada pixel.Em estudo para áreas de Cerrado e Cana-de-açúcar, Santos et al. (2015) obtiveram valores inferiores para a metodologia METRIC em comparação com a SEBAL, porém, com uma diferença entre elas inferior às observadas nesse estudo, sendo que o melhor desempenho ocorreu para a primeira. As duas metodologias, no entanto, superestimaram as medidas de campo.

Os maiores valores de saldo de radiação foram observados no norte da BHRP para ambas as metodologias empregadas e cenas, conforme Figura 9. Resultado já esperado, por tratar-se de áreas onde ocorrem elevados valores de NDVI, comprovando que áreas com maior quantidade de vegetação retém uma maior quantidade de energia (saldo de radiação) quando comparadas com áreas de vegetação rala ou solo descoberto. Ainda, os resquícios dos maiores valores do saldo são observados na serra de Ibiapaba, nordeste da bacia, tendo maior destaque na metodologia METRIC.

A metodologia SEBAL (cena 2015) apresentou uma diminuição do saldo de radiação na porção sudeste da bacia com relação ao ano de 2005, essa região corresponde a uma porção antropizada com resquícios de Caatinga, conforme Figura 5. A cena de 2005 (SEBAL) 
apresentou maior região com valores superiores a 660 $\mathrm{Wm}^{-2}$, em relação ao ano de 2015 . Ainda, ao observar a cena (2005), além da abrangência da região norte com valores máximos de saldo, esse se estende até a região sudeste da BHRP. O comportamento dos valores máximos se mantém na cena 2005 correspondente a metodologia METRIC, porém para valores superiores a $480 \mathrm{Wm}^{-2}$.

Os menores valores do saldo são observados em ambas as cenas e metodologias na região sudoeste da BHRP, essa corresponde à vegetação do tipo savanas (Figura 6). Nessa área ocorre predominância dos valores do saldo entre 580 e $620 \mathrm{Wm}^{-2}$ para o método SEBAL, e valores entre 420 e $480 \mathrm{Wm}^{-2}$ para o METRIC.

Para áreas de Savana em recuperação, Santos (2015) encontrou, para o dia 18 de junho de 2013, valor de saldo de radiação instantâneo de $642,9 \mathrm{Wm}^{-2}$ utilizando metodologia semelhante à SEBAL, sendo o desvio padrão com relação aos 16 dias estudados de 54,1 Wm2. Em metodologia semelhante à METRIC, com diferença para o cômputo da água precipitável, estimada diretamente com o sensor MODIS, a mesma autora obteve o valor de $618,6 \mathrm{Wm}^{-2}$, com desvio padrão de $57,8 \mathrm{Wm}^{-2}$. A partir das medidas de campo o valor encontrado foi de 562,7 $\mathrm{Wm}^{-2}$, apresentando um desvio padrão de 43,5 $\mathrm{Wm}^{-2}$. Nicácio (2008) utilizando o sensor MODIS/Aqua revelou em região de savana estépica densa valores em torno de 613,0 a 669,0 $\mathrm{Wm}^{-2}$, para área de solo exposto ou de vegetação nativa muito esparsa, as estimativas estiveram na faixa que vai de aproximadamente 510,0 a $572,0 \mathrm{Wm}^{-2}$.

$\mathrm{Na}$ falta de medidas de campo e, considerando-se os valores da literatura anteriormente expostos, a metodologia SEBAL parece estar mais próxima dos valores esperados. Fato, porém, é que nos dois casos ficam evidenciados diferentes valores de saldo para diferentes tipos de cobertura da superfície e, ainda resultando em maiores valores para os alvos esperados: onde há maior quantidade de vegetação (maior NDVI) e em corpos hídricos. 
Figura 9 - Saldo de radiação $\left(\mathrm{Wm}^{-2}\right)$ obtido através das metodologias METRIC (M) e SEBAL (S) para a BHRP.

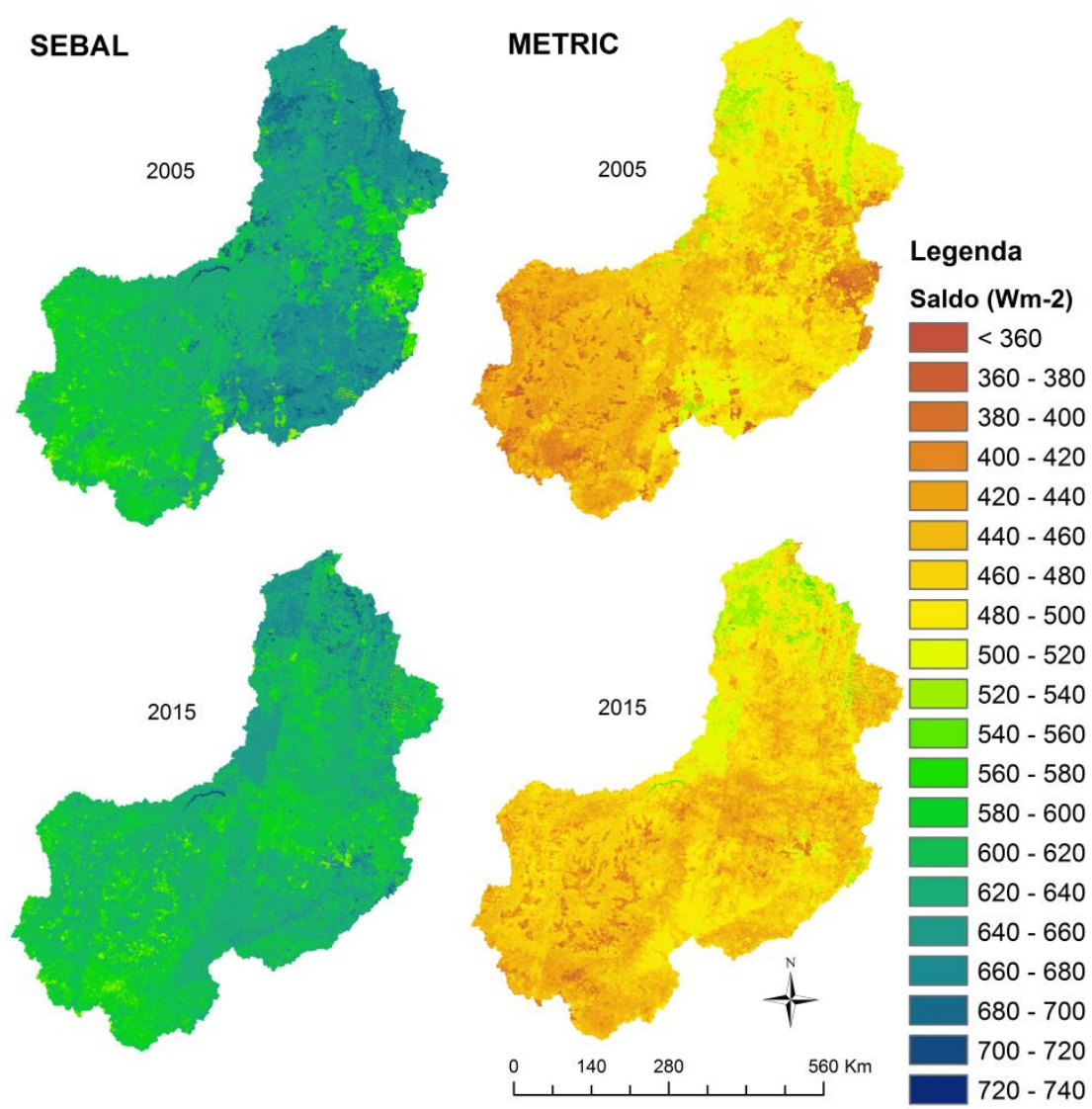

Fonte: Os autores (2016)

Tabela 6 - Informações sobre as características biofísicas e saldo de radiação da BHRP.

\begin{tabular}{lcccccc}
\hline Variáveis & $\begin{array}{c}\text { Albedo } \\
(\mathrm{L}) 2005\end{array}$ & $\begin{array}{c}\text { Albedo } \\
(\mathrm{T}) 2005\end{array}$ & $\begin{array}{c}\text { Albedo } \\
(\mathrm{L}) 2015\end{array}$ & $\begin{array}{c}\text { Albedo } \\
(\mathrm{T}) 2015\end{array}$ & $\begin{array}{c}\text { NDVI } \\
2005\end{array}$ & $\begin{array}{c}\text { NDVI } \\
2015\end{array}$ \\
\hline Mínimo & $-0,53$ & $-0,36$ & $-0,22$ & $-0,09$ & $-1,28$ & $-1,51$ \\
Máximo & 0,65 & 0,65 & 0,70 & 0,69 & 0,94 & 0,95 \\
Média & 0,13 & 0,12 & 0,14 & 0,13 & 0,63 & 0,56 \\
*Desvio & 0,02 & 0,02 & 0,02 & 0,02 & 0,14 & 0,14 \\
**CV & 0,15 & 0,17 & 0,14 & 0,15 & 0,22 & 0,25 \\
\hline \multirow{2}{*}{ Variáveis } & Temp. & Temp. & Saldo & Saldo & Saldo & Saldo \\
& 2005 & 2015 & $(\mathrm{~S}) 2005$ & $(\mathrm{M}) 2005$ & $(\mathrm{~S}) 2015$ & $(\mathrm{M}) 2015$ \\
\hline Mínimo & 293 & 293 & 175,38 & 116,09 & 152,48 & 115,57 \\
Máximo & 316,32 & 315,70 & 1181,06 & 787,48 & 1004,71 & 741,21 \\
Média & 302,60 & 304,46 & 629,99 & 461,70 & 617,12 & 465,63 \\
*Desvio & 2,43 & 2,51 & 33,63 & 32,61 & 24,95 & 27,13 \\
**CV & 0,008 & 0,008 & 0,05 & 0,07 & 0,04 & 0,06 \\
\hline
\end{tabular}

*Desvio padrão **Coeficiente de variação

Fonte: Os autores (2016) 


\section{CONSIDERAÇÕES FINAIS}

Com base na análise do coeficiente de compacidade e o fator de forma, a bacia apresenta forma mais alongada, não sendo, portanto suscetível a enchentes em situações normais de precipitação. A BHRP apresentou baixa densidade de drenagem. A altitude média é de 354,68 m e as regiões de maior elevação se encontram na Serra de Ibiapaba no estado do Ceará e nas nascentes de rios localizadas no sudoeste da região. Ocorre predominância da declividade do tipo plana. O canal fluvial principal apresenta baixa declividade e formas transicionais, regulares e irregulares em seu percurso.

As variáveis biofísicas como albedo e NDVI mostraram-se notadamente diferenciadas para diferentes tipos de cobertura do solo, evidenciando uma maior disponibilidade de energia para áreas com maior cobertura vegetal. Dessa forma as áreas com os maiores valores de NDVI apresentaram consequentemente menores valores de albedo e temperatura da superfície, o que corrobora com um maior valor de saldo de radiação, como é o caso da porção noroeste da bacia.

\section{AGRADECIMENTOS}

A Fundação de Amparo à Pesquisa e Desenvolvimento Científico e Tecnológico do Maranhão (FAPEMA) pelo apoio e disponibilidade dos recursos necessários para a realização do presente trabalho.

\section{REFERÊNCIAS BIBLIOGRÁFICAS}

ALLEN, R. G.; TASUMI, M.; TREZZA, R. Satellite-based energy balance for mapping evapotranspiration with internalized calibration (METRIC) - Model. JournalofIrrigationandDrainageEngineering, v.133, n.4, p.380-394, 2007.

ALLEN, R. G.; TREZZA, R.; TASUMI M. Surface energy balance algorithms for land. Advance training and user's manual, version 1.0, 2002, 98p.

ALLEN, R. G.; PEREIRA, L. S.; RAES, D.; SMITH, M. Crop evapotranspiration Guidelines for computing crop water requirements - FAO. Irrigation and drainage, paper 56. Rome, Italy, 318p, 1998. 
ALLEN, R. G. Assessing integrity of weather data for use in reference evapotranspiration estimation. Journal of Irrigation and Drainage Engineering, v.122, p.97-106, 1996.

ALVES, J. M. P.; CASTRO, P. T. A. Influência de feições geológicas na morfologia da bacia do rio do Tanque (MG) baseada no estudo de parâmetros morfométricos e análise de padrões de lineamentos. Revista Brasileira de Geociências, v. 33, n.2, p.117-124, 2003.

ANA. Agência Nacional de Águas. 2016. Disponível em: $<$ http://hidroweb.ana.gov.br/HidroWeb.asp?TocItem=1080\&TipoReg=7\&MostraCon=false \& CriaArq=false \&TipoArq=1\&SerieHist=true >. Acesso em: 10 mar. 2016.

ANDRADE, R. G. Aplicação do algoritmo SEBAL na estimativa da evapotranspiração e da biomassa acumulada da cana-de-açúcar. Tese (Doutorado em Meteorologia Agrícola). Universidade Federal de Viçosa, Minas Gerais, 2008.

ASCE-EWRI. The ASCE standardized reference evapotranspiration equation. 2005. Disponível em: <http://www.kimberly.uidaho.edu/water/asceewri/ascestzdetmain20 05.pdf>. Acessoem: 10 jan. 2016.

BASTIAANSSEN, W. G. M. SEBAL-based sensible and latent heat fluxes in the irrigated Gediz Basin, Turkey. JournalofHydrology, v.229, n.1, p.87-100, 2000.

BASTIAANSSEN, W. G. M.; MENENTI, M.; FEDDES, R. A.; HOLTSLAG, A. A. M. A remote sensing surface energy balance algorithm for land (SEBAL). 1: Formulation. Journal of Hydrology, v.212-213, p.198-212, 1998.

BASTIAANSSEN, W. G. M. Regionalization of surface flux densities and moisture indicators in composite terrain: A remote sensing approach under clear skies in Mediterranean climates. Ph.D. Dissertation, CIP Data KoninklijkeBibliotheek, Den Haag, The Netherlands. 1995.

BEZERRA, J. M.; MOURA, G. B. de A.; SILVA, B. B.; LOPES, P. M. O.; SILVA, E. F. de F. Parâmetros biofísicos obtidos por sensoriamento remoto em região semiárida do estado do Rio Grande do Norte, Brasil. Revista Brasileira de Engenharia Agrícola e Ambiental, v. 18, n. 1, p. 73-84, 2014.

BISHT, G.; BRAS, R. L. Estimation of net radiation from the MODIS data under all sky conditions: Southern Great Plains case study. Remote SensingofEnvironment, v.114, n.7, p.1522-1534, 2010.

BISHT, G.; VENTURINI, V.; ISLAM, S.; JIANG, L. Estimation of the net radiation using MODIS (Moderate Resolution Imaging Spectroradiometer) data for clear-sky days. Remote Sensing of Environment, v.97, n.1, p.52-67, 2005. 
BRASIL. Caderno da Região Hidrográfica do Parnaíba. 2006. Disponível em: <http://www.mma.gov.br/estruturas/161/_publicacao/161_publicacao03032011023605.pdf>. Acesso em: 04 mar. 2013.

CARDOSO, C. A.; DIAS, H. C. T.; SOARES, C. P. B.; MARTINS, S. V. Caracterização morfométrica da bacia hidrográfica do rio Debossan, Nova Friburgo, RJ. RevistaÁrvore, v. 30, n. 2, p. 241-248, 2006.

DUFFIE, J. A.; BECKMAN, W. A. Solar engineering of thermal process. New York: Wiley, 2. ed. 1991.

GARCEZ, L. N.; ALVAREZ, G. A. Hidrologia. São Paulo: Edgard Blücher, 2. ed. 1988. $291 \mathrm{p}$.

GARRISON, J. D.; ADLER, G. P. Estimation of precipitable water over the United States for application to the division of solar radiation into its direct and diffuse components. Solar Energy, v.44, 225-241, p.1990.

IBGE. Mapas interativos, 2013. Disponível em: <ftp://geoftp.ibge.gov.br/mapas_in terativos/>. Acesso em: 20 maio 2016.

INMET. Banco de Dados Meteorológicos para Ensino e Pesquisa (BDMEP). Disponível em: <http://www.inmet.gov.br/projetos/rede/pesquisa/>. Acessoem: 10 maio 2016.

LIANG, S. Narrowband to broadband conversions of land surface albedo I Algorithms. Remote SensingofEnvironment, v.76, p. 213- 238, 2000.

MILANI, J. R.; CANALI, N. E. Analise morfométrica do complexo hidrográfico do rio matinhos por uma analise morfométrica. Curitiba: Revista RA'EGA, n.4, p. 139-152, 2000.

MIRANDA, E. E. de; (Coord.). Brasil em Relevo. Campinas: Embrapa Monitoramento por Satélite, 2005. Disponível em: <http://www.relevobr.cnpm. embrapa.br〉. Acesso em: 8 jan. 2016.

NICÁCIO, R. M. Evapotranspiração real e umidade do solo usando dados de sensores orbitais e a metodologia SEBAL na bacia do rio São Francisco. 337f. Tese (Doutorado em Engenharia Civil), Universidade Federal do Rio de Janeiro, Rio de Janeiro, 2008.

OLIVEIRA, É. D.; BORSATO, V. A. Propriedades morfométricas da bacia hidrográfica hidrográfica do córrego Marumbizinho, Jandaia do Sul/PR. Revista Geografar, v.6, n.1, p.7694, 2011.

OLIVEIRA, L. M. M. Estimativa da evapotranspiração real por sensoriamento remoto na Bacia do Rio Tapacurá-PE. Tese (Doutorado em Engenharia Civil), Universidade Federal de Pernambuco. Recife, 2012. 
SANTOS, F. A. C. Estimativa dos Fluxos de $\mathrm{CO}_{2}$ e Evapotranspiração em Áreas de Caatinga em Recuperação e Degradada no Estado da Paraíba. 122 f. Tese (Doutorado em meteorologia), Universidade Federal de Campina Grande, 2015.

SANTOS, F. A. C.; SANTOS, C. A. C.; SILVA, B. B.; ARAÚJO, A. L.; CUNHA, J. E. B. L. Desempenho de metodologias para estimativa do saldo de radiação a partir de imagens MODIS. Revista Brasileira de Meteorologia, v. 30, n. 3, p. 295 - 306, 2015.

SANTOS, F.A.C. Alterações no balanço radiativo e impactos climáticos decorrentes do uso da terra no estado de São Paulo. 83f. Dissertação (Mestrado em Meteorologia), Universidade Federal de Campina Grande, 2011.

SILVA, B. B. DA; LOPES, G. M.; AZEVEDO, P. V. Balanço de Radiação em Áreas Irrigadas Utilizando Imagens Landsat 5-TM. RevistaBrasileira de Meteorologia, v.20, n.2, p.243-252, 2005.

STRAHLER, A.N.Quantitative geomorphology of drainage basins and channel networks. In: CHOW, V.T. (Ed.). Handbook of applied Hidrology. New York: McGraw-Hill. p. 439-476, 1964.

TASUMI, M.; ALLEN, R. G.; TREZZA, R. At-surface reflectance and albedo from satellite for operational calculation of land surface energy balance. Journal of Hydrologic Engineering, v.13, p.51-63, 2008.

TASUMI, M.; ALLEN, R. G.; TREZZA, R.;WRIGHT, J. L. Satellite-Based Energy Balance to Assess Within-Population Variance of Crop Coefficient Curves. Journal of Irrigation and Drainage Engineering, p.94-108, 2005.

TEIXEIRA, A. H. C.; BASTIAANSSEN, W. G. M.; AHMAD, M. D.; MOURA, M. S. B.; BOS, M. G. Analysis of energy fluxes and vegetation-atmosphere parameters in irrigated and natural ecosystems of semi-arid Brazil. Journal of Hydrology, v. 362, p. 110- 127, 2008.

VILLELA, S. M.; MATTOS, A. HidrologiaAplicada. São Paulo: McGraw-Hill do Brasil, $1975,245 \mathrm{p}$.

WITHANAGE, N.S.; DAYAWANSA, N.D.K.; SILVA, R.P. Morphometric Analysis of the Gal Oya River Basin Using Spatial Data Derived from GIS. Tropical AgriculturalResearch, v.26, n.1, p. 175-188, 2014. 